\title{
Dynamic research of carriage system of the angle measuring comparator
}

\author{
A. Kilikevičius*, A. Kasparaitis**, V. Prokopovič̌***, A. H. Marcinkevičius****, \\ K. Kilikevičiené******, R. Jasevičius******* \\ *Vilnius Gediminas Technical University, Sauletekio 11, 10223 Vilnius, Lithuania, E-mail: arturas.kilikevicius@vgtu.lt \\ **Vilnius Gediminas Technical University, Sauletekio 11,10223Vilnius, Lithuania, E-mail: albinas.kasparaitis@vgtu.lt \\ ***Vilnius Gediminas Technical University, Saulètekio 11, 10223 Vilnius, Lithuania, \\ E-mail: valdemar.prokopovic@vgtu.lt \\ ****Vilnius Gediminas Technical University, Saulètekio 11, 10223 Vilnius, Lithuania, \\ E-mail: andrejus.marcinkeviciuss@vgtu.lt \\ ****Vilnius Gediminas Technical University, Saulètekio 11, 10223 Vilnius, Lithuania, \\ E-mail: kristina.kilikevičienėvgtu.lt \\ *****Vilnius Gediminas Technical University, Saulètekio 11, 10223 Vilnius, Lithuania, \\ E-mail: raimondas.jasevicius@vgtu.lt
}

cross $^{\text {ref }}$ http://dx.doi.org/10.5755/j01.mech.22.2.13982

\section{Introduction}

Currently, remote sensing technology is widely used. The new remote sensing technology requires the modern and specific accuracy of measurement and calibration [1-6]. In known literature, it could be found different type of problems related to the precision of the mechatronical systems, which are designed for the angle measurements [211]. The maximum stiffness of the construction must be applied or at least pursued in the design of precision systems. Also "Open" shell structures and structural elements loaded by bending strains should be avoided. Thus, it is necessary for the underlying principles ensuring. However, this is not always easy because inevitably a compromise must be found, balancing initial cost, functionality of the mechanical system, stiffness of the structural elements, dimensions, etc.

Angle comparators are designed to perform precise and even ultra-precise measurements. Because of a highly precision the angle comparator must be properly isolated from floor vibrations. The passive vibration isolation does not consume electricity and is cost effective [12-14]. However, the main problem is to minimize residual vibrations, which are caused by a soft flexible mounting support with the passive vibration isolators. This flexible mounting support has a fundamental natural frequency. In most cases, the residual vibration isolation equipment gets a low frequency of vibrations due to internal and external excitation, with most occurring excitation is caused by moving parts of the machine $[13,14,16]$. Residual vibration must be minimized, since it reduces the final precision of the angle comparator a control theoretic framework for optimally locating passive vibration isolators need to minimize residual vibration].

This paper presents measuring methodology of a simulation of dynamics as well as its characteristics for the precise angle measurement mechanisms. The physical experiments were prepared in order to test dynamic model and to analyse the hinge type mechanism.

It is presented multibody mechanisms, which have hinges as well as clearance space. In order to investigate characteristics of dynamics, numerical methods were implemented. Clearance space in mechanisms is inevitable for meeting the errors during production and wear of mechanical components. Moreover, clearance space can be in each hinges connector during the motion of mechanism.

The motion of real mechanism is different in comparison with idealistic (theoretical) mechanism, while the precision of motion is decreasing due to increase of clearance space of a hinges connection. Clearance space in hinge connections is a reason of the impacts at dynamic loads, which cause load transfer in a system. Thus, the mechanism may be damaged. The clearance space has the influence of the respond time of a system (dynamic response) and because of this it causes the difference between the theoretical and real model measurements and motion [1-12]. The main aim of the research is to determine (by experiment) the dynamic characteristics of multibody mechanical systems of the angle comparator carriage on which optical system is attached to it and to compare the experiment with the results obtained by theoretical calculations.

\section{Object of research and measurement equipment}

The object of investigation is JSC „Precizika Metrology“ developed angle measurement comparator (Fig. 1, a) with vibrant-stable base, which is made of massive grey fine-grained granite brick. Here is the additionally installed system in order to compare the angle. This system contains precise aero-static spindle, gear and angle measurement mechanisms. The spindle is connected with the centering and the flattening table in order to calibrate and mounting the limb.

On the granite base through rigid supports mounted on rigid granite straight motion guides for which with aerostatic supporting bearings are programmatically controlled actuator biases and the carriage (material steel 45) is fixed on the set point position. While on carriage is mounted limb scale position detecting device.

The spindle rotates the worm-gear trough, while the worm-gear is an axial direction supported by the aerostatic bearing, and the radial direction is supported by the 
roll bearings. These aero-static and rolling bearings are installed in subassemblies of their positioning. Radial and axial forces acting on these bearings are decreased by the elastic element connection of spindle and worm wheel. It produces the pure drive torque, which is done by a motor to the spindle and transmitted via the worm wheel and reducer. Alternatively, the spindle can be rotated manually, so in this case the reducer will be disconnected.

The calibration procedure is controlled, the data of the calibration results are stored, collected, processed and presented automatically into computing - management complex. This complex consists of computer, controllers and other equipment, and equipped with software that supports the mathematical calculations. The processes of angle sensor calibration procedure, take place at the resonance frequencies should be avoided.

The following measurement equipment (Fig. 1, b) was used for modal analysis of an exploratory system with triaxial accelerometer 4506 (Frequency range $0.6-3000 \mathrm{~Hz}$; Sensitivity $100 \mathrm{mV} / \mathrm{g}$ ) (Fig. 1, c). During the experiment, sensors have been selected assessing similar research experience.

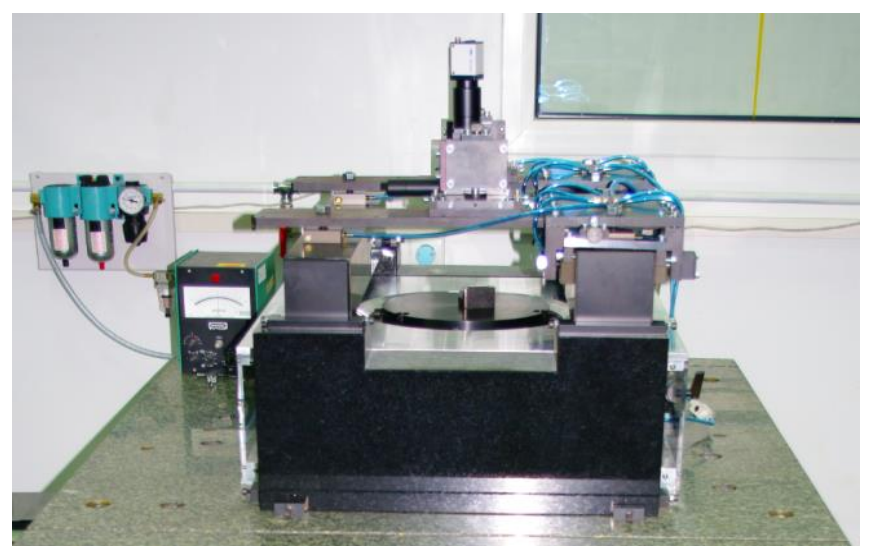

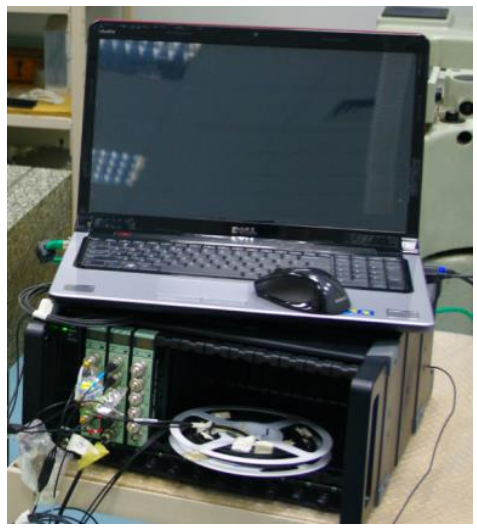

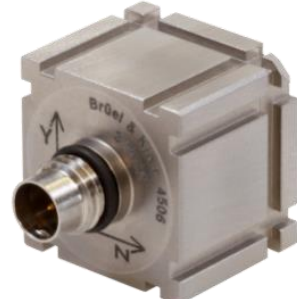

Fig. 1 General view of: a - carriage of angle measurement comparator; b - measurement equipment; $\mathrm{c}$ - in the measurement used triaxial accelerometer

\section{Modelling of mechanical system of angle comparator}

Angle measurement comparator carriage modal analysis was performed with the SolidWorks program. Material influence on the carriage elastic vibrations was investigated. Here the analysis was performed for freely selected steel 45 and stainless steel AISI 304 materials. The aim of the simulation (with improved material of carriage) is to find out how dynamic characteristics are changing.

Mesh information show in Table 1. The comparison of two different type material carriages oscillation and deformation using dangerous excitation frequency is shown in Table 2.

Mesh Information

\begin{tabular}{|l|l|}
\hline Mesh type & Solid Mesh \\
\hline Mesher Used: & Standard mesh \\
\hline Automatic Transition: & Off \\
\hline Include Mesh Auto Loops: & Off \\
\hline Jacobian points & 4 Points \\
\hline Element Size & $4.58312 \mathrm{~mm}$ \\
\hline Tolerance & $0.249 \mathrm{~mm}$ \\
\hline Mesh Quality & High \\
\hline \multicolumn{1}{|c|}{ Mesh Information - Details } \\
\hline Total Nodes & 107410 \\
\hline Total Elements & 66742 \\
\hline Maximum Aspect Ratio & 21.634 \\
\hline \% of elements with Aspect Ratio <3 & 93.8 \\
\hline \% of elements with Aspect Ratio > 10 & 0.0569 \\
\hline \% of distorted elements (Jacobian) & 0 \\
\hline
\end{tabular}

Model of the angle comparator carriage. The behaviour of any elastic object interacting with dynamic forces can be specified by the dynamic equilibrium equation [13]:

$$
[M]\{\ddot{\delta}\}+[C]\{\dot{\delta}\}+[K]\{\delta\}=\{F\}
$$

where $[M],[C],[K]$ are the mass, damping and stiffness matrices, respectively; $\{F\}$ is the vector of external mechanical forces; $\{\ddot{\delta}\}=\left\{d^{2} \delta / d^{2} t\right\},\{\dot{\delta}\}=\{d \delta / d t\},\{\delta\}$ are the vectors of accelerations, velocities and displacements, respectively.

For the process when there is no forced deformation and no damping, the equation is further simplified to: 


$$
[M]\{\ddot{\delta}\}+[K]\{\delta\}=\{0\}
$$

The non-zero periodic solutions of this equation have the form:

$$
\{\delta\}=\left\{\delta_{0}\right\} \cos \omega t
$$

After differentiation the equilibrium equation is expressed as:

$$
\left([K]+\omega^{2}[M]\right)\left\{\delta_{0}\right\}=\{0\} .
$$

By solving this eigenvalue problem the eigenfrequencies $\omega_{i}$ and the eigenmodes $\left\{\delta_{i}\right\}$ are obtained, here $i=1,2, \ldots, n$ and $n$ is the number of degrees of freedom of the structure. The eigenvectors are stored in a matrix:

$$
[\Delta]=\left[\left\{\delta_{1}\right\}\left\{\delta_{2}\right\} \cdots\left\{\delta_{n}\right\}\right]
$$

The scale of the eigenmodes is chosen so that the foolowing condition is satisfied:

$$
\left\{\delta_{i}\right\}^{T}[M]\left\{\delta_{i}\right\}=1 .
$$

Then the conditions of orthogonality hold:

$$
[\Delta]^{T}[M][\Delta]=[I]
$$

where $[I]$ is the identity matrix.

The motion is expressed by the linear combination of the eigenmodes:

$$
\{\delta\}=[\Delta]\{z\}=[\Delta]\left\{\begin{array}{c}
z_{1} \\
z_{2} \\
\vdots \\
z_{n}
\end{array}\right\},
$$

where $\{z\}$ is the vector of the coefficients of the eigenmodes $z_{1}, z_{2}, \ldots, z_{n}$.

Modal equations have the form:

$$
\ddot{z}_{i}[M]\left\{\ddot{z}_{i}\right\}+2 c_{i} \omega_{i} \dot{z}_{i}+\omega_{i}^{2} z_{i}=\left\{\delta_{i}\right\}^{T}\{F\},
$$

where the modal damping $c_{i}$ is expressed as:

$$
c_{i}=1 / 2\left(\alpha / \omega_{i}+\beta \omega_{i}\right) .
$$

Simulation result

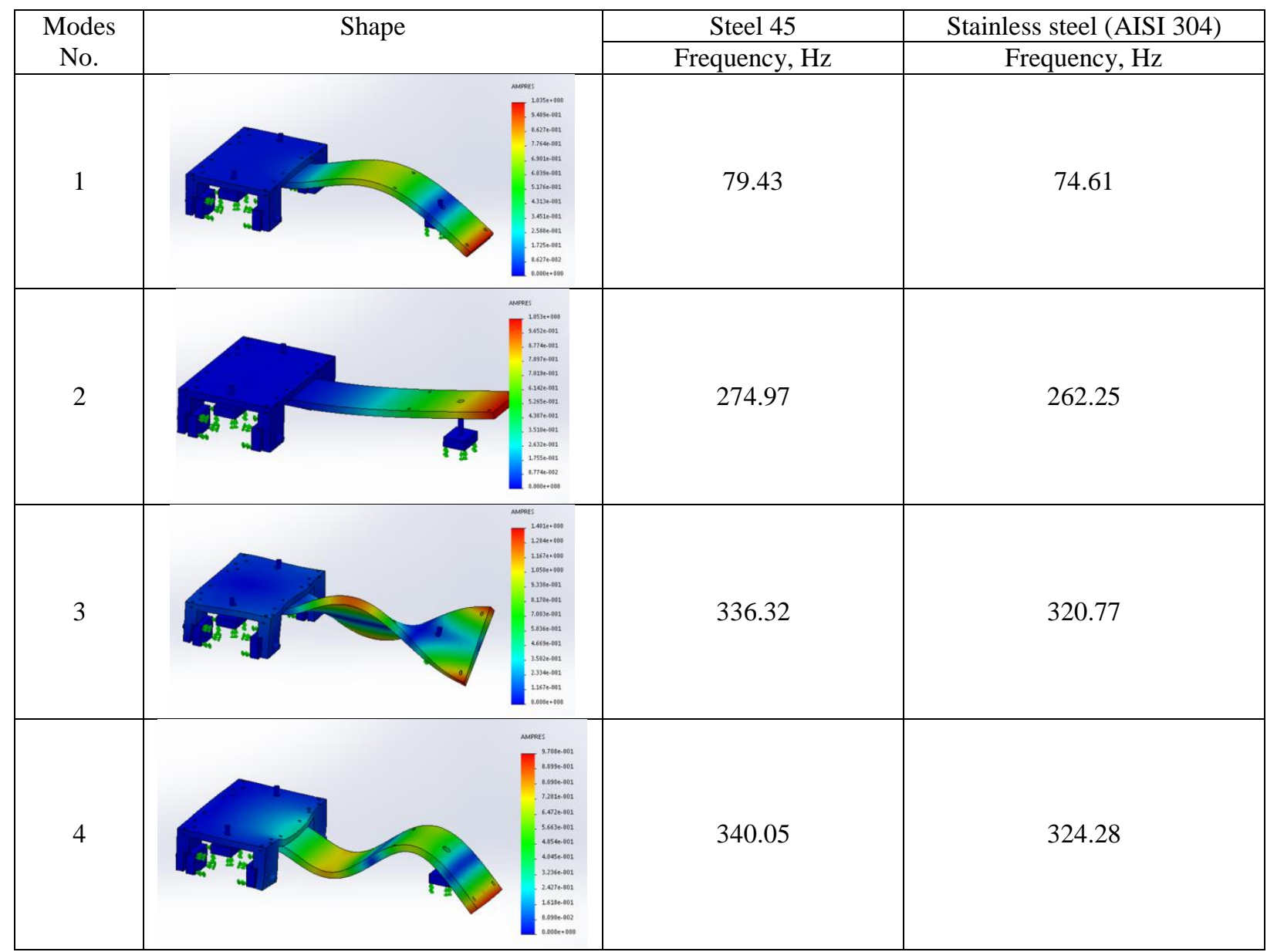

The results of the simulation show that in the carriage occur elastic deformations, which give negative side effect on the precision of calibration. It causes uncontrolled additional movement of device, which detects the position raster elements. Looking from the precision point of view in our case the most dangerous is the first mode.

The carriage motion shape using the first mode frequency leads to angle measurement comparator carriage 
parts displacements at $\mathrm{X}$ and $\mathrm{Y}$ directions. The displacement at $\mathrm{X}$ direction is perpendicular to the axis of raster elements. Due to this displacement, resulting stochastic calibration error maximum value is equal to the maximum amount of displacement.

Other dangerous mode shapes are 3 and 4 of the resonant frequency. With these frequencies carriage construction deforms in a local place, where the line detection microscope is mounted. Moreover, this local deformation directly affects the measurement precision. The simulation results show that material characteristics did not have any significant effect on elastic deformations of vibrating carriage. The manner of carriages does not change, while the difference between the frequencies of the modes is less than $5 \%$.

Accomplished simulation of carriage using different materials have shown that change of the resonant frequency is up to $5 \%$. This change of dynamic characteristics is insignificant.

\section{The experimental investigations}

The experimental investigations consist of two parts: an experimental modal analysis and the relative vibration measurement of the microscope in accordance with rotating table. Relative vibrations show vibrations during the working regime, while modal analysis shows the carriage system modal parameters.

The Operational Modal Analysis (OMA) of an angle comparator carriage. Operational modal analysis is the process by which with experimental data can be determined the modal parameters (natural frequency, damping ratio and mode shape). Modal parameters are set in the selected frequency range (the interval). Mode shape structure (object) deflection, which represents a specific mode of relative displacement between the structure (object) parts.

It was comparator carriage operational modal analysis performed. It measured in the 36 points in three directions. The results of the operation modal analysis of the comparator carriage are shown in Fig. 2.

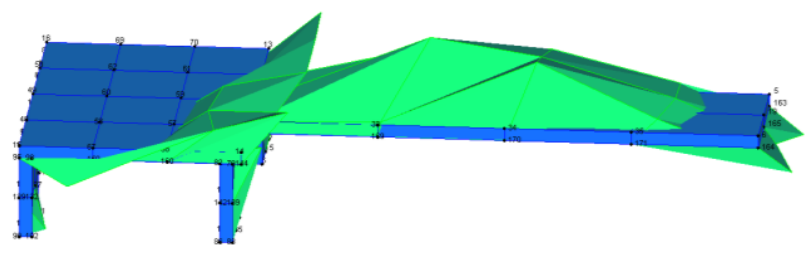

a

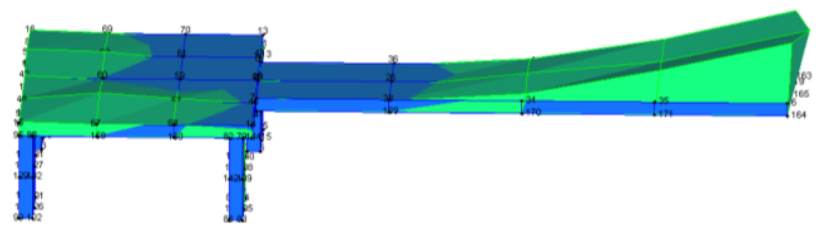

b

Fig. 2 Experimental measurement of the angle comparator carriage modal analysis: $\mathrm{a}-1$ mode shape; $\mathrm{b}-2$ mode shape

After the experimental measurement of the angle comparator carriage modal analysis identified four modes shapes, its frequencies are 76 and $264 \mathrm{~Hz}$ (Fig. 2). These modes correspond to the theoretical simulation (Table 2) 1 and 2 modes. Comparing theoretical and experimental modal analysis result data obtained by the mismatch $4 \%$ of frequency.

Angle comparator carriage vibrations affect angle measurement accuracy. Since the CCD camera is attached to the carriage comparator angle, an angle measurement error is directly proportional to the CCD camera displacements.

Carriage vibrations at $\mathrm{z}$-axis direction defocus optical system for measuring the position of the lines. This reduces calibration accuracy.

Carriage linear movement and deformations change the detecting system position in accordance with the limb. This has a direct effect on the measurement accuracy and the resulting position errors.

Carriage angular displacements and deformations change the angular position of the optical system in accordance with the limb. It has the same impact as previously mentioned linear displacements and deformations.

\section{Conclusions}

1. In order to get high- precision calibration of the angle and simulation of dynamic effects associated with the calibration error must be evaluated elastic deformation related to vibrations of environmental and internal sources.

2. Using the software package SolidWorks has tested sensitive to vibrations precision angle comparator compound carriage as deformable body and identify dangerous resonant frequencies and carriage deformation. These deformations increasing the angle of calibration error raster element position detection device displacements in accordance with the calibration object. Modal analysis was also taken into account construction weaknesses and reduction of deformations that leads to calibration errors.

3. Experimental modal analysis on angle comparator carriage has been completed in order to identify 2 modes: 76 and $264 \mathrm{~Hz}$.

4. Basing on these relative displacements between the measuring system and the optical detection system calibration errors can be identified. Generally, these relative displacements lead to calibration errors.

5 . In order to increase the accuracy of measurement of the angle comparator the elastic deformations must be evaluated. These elastic deformations occur when basic details vibrate in resonance frequencies.

\section{References}

1. Flores, P.; Ambrosio, J.; Claro, J.C.P.; Lankarani, H.M.; Koshy, C.S. 2006. A study on dynamics of mechanical systems including joints with clearance and lubrication, Mechanism and Machine Theory 41: 247-261. http://dx.doi.org/10.1016/j.mechmachtheory.2005.10.002.

2. Erkaya, S.; Uzmay, I. 2008. A neural-genetic (NN-GA) approach for optimizing mechanisms having joints with clearance, Multibody System Dynamics 20(1): 69-83. http://dx.doi.org/10.1007/s11044-008-9106-6.

3. Flores, P. 2009. Modeling and simulation of wear in revolute clearance joints in multi-body systems, Mechanism and Machine Theory 44(6): 1211-1222. 
http://dx.doi.org/10.1016/j.mechmachtheory.2008.08.003.

4. Flores, P. 2010. A parametric study on the dynamic response of planar multi-body systems with multiple clearance joints, Nonlinear Dynamics 61: 633-653. http://dx.doi.org/10.1007/s11071-010-9676-8.

5. Garcia, O.J.C. 2005. Analysis of clearance in multibody system, Multibody System Dynamics13: 401-420. http://dx.doi.org/10.1007/s11044-005-3989-2.

6. Erkaya, S.; Uzmay, I. 2010. Experimental investigation of joint clearance effects on the dynamics of a slidercrank mechanism, Multibody System Dynamics 24: 81102. http://dx.doi.org/10.1007/s11044-010-9192-0.

7. Bauchau, O.A.; Rodriguez, J. 2002. Modeling of joints with clearance in flexible multi-body system, International Journal of Solids and Structures 34: 41-63.

8. Flores, P.; Ambrósio, J. 2010. On the contact detection for contact-impact analysis in multibody systems, Multibody System Dynamics 24(1): 103-122. http://dx.doi.org/10.1007/s11044-010-9209-8.

9. Schwab, A.L.; Meijaard, J.P.; Meijers, P.A. 2002. Comparison of revolute joint clearance model in the dynamic analysis of rigid and elastic mechanical systems, Mechanism and Machine Theory 37(9): 895-913. http://dx.doi.org/10.1016/S0094-114X(02)00033-2.

10. Ting, K.L.; Zhu, J.D.; Watkins, D. 2000. The effects of joint clearance on position and orientation deviation of linkages and manipulators, Mechanism and Machine Theory 35: 391-401. http://dx.doi.org/10.1016/S0094-114X(99)00019-1.

11. Tian, Q.; Zhang, Y.Q.; Chen, L.P.; Flores, P. 2009. Dynamics of spatial flexible multibody systems with clearance and lubricated spherical joints, Computers and Structures 87: 913-929. http://dx.doi.org/10.1016/j.compstruc.2009.03.006.

12. Debra, D.B. 1992. Vibration isolation of precision machine tools and instruments, Annals of the CIRP 41: 711-718.

http://dx.doi.org/10.1016/S0007-8506(07)63257-0.

13. Tekili, S.; Khadri, Y.; Merzoug, B. 2015. Finite element analysis of free vibration of beams with composite coats, Mechanika 21(4): 290-295.

http://dx.doi.org/10.5755/j01.mech.21.3.9849.

14. Rivin, E.I. 1995. Vibration isolation of precision equipment, Precision Engineering 17: 41-56. http://dx.doi.org/10.1016/0141-6359(94)00006-L.

15. Rivin, E.I. 2006. Vibration isolation of precision objects, Journal of Sound and Vibration 40: 12-20.

16. Subrahmanyari, P.K.; Trumper, D.L. 2000. Synthesis of passive vibration isolation mounts for machine tools - a control systems paradigm, In: Proc. American Control Conference, Chicago, IL. June, 2886-2891.

A. Kilikevičius, A. Kasparaitis, V. Prokopovič, A. H. Marcinkevičius, K. Kilikevičienè, R. Jasevičius

\section{DYNAMIC RESEARCH OF CARRIAGE SYSTEM OF THE ANGLE MEASURING COMPARATOR}

S u m m a r y

With modern equipment it is possible to implement calibration during dynamic regime, when the location of raster elements of measured object is detected during the motion of movable components of measurement equipment. During this process it is acting external as well as internal sources of vibration. In this work the object of investigation is originally developed angle measurement comparator. The main aim of this research is to determine the dynamic characteristics of multibody mechanical systems of the angle comparator carriage on which optical system is attached to it and to compare the experiment with the results obtained by theoretical calculations.

Keywords: angle measurement comparator, modal analysis, vibrations, elastic deformation, dynamic characteristics, multibody mechanical systems, comparator carriage.

Received January 04, 2016

Accepted April 05, 2016 